\title{
Operative treatment of metastatic breast cancer in the spine with regard to molecular phenotypes
}

\author{
Daniel Adler, Wojciech Pepke, Michael Akbar \\ Spine Center, Department of Orthopaedic Surgery, Trauma Surgery and Division of Spinal Cord Injury, Ruprecht-Karls-University, \\ Heidelberg 69118, Germany. \\ Correspondence to: Dr. Michael Akbar, Spine Center, Department of Orthopaedic Surgery, Trauma Surgery and Division of \\ Spinal Cord Injury, Ruprecht-Karls-University, Schlierbacher Landstrasse 200a, Heidelberg 69118, Germany. \\ E-mail: Michael.Akbar@med.uni-heidelberg.de
}

How to cite this article: Adler D, Pepke W, Akbar M. Operative treatment of metastaticbreast cancer in the spine with regard to molecular phenotypes. J Cancer Metastasis Treat 2019;5:45. http://dx.doi.org/10.20517/2394-4722.2019.03

Received: 2 Jan 2019 First Decision: 18 Feb 2019 Revised: 19 Mar 2019 Accepted: 10 Apr 2019 Published: 31 May 2019

Science Editor: William Schiemann Copy Editor: Cai-Hong Wang Production Editor: Huan-Liang Wu

\begin{abstract}
With more than one million new diseases per year breast cancer is the most common malignancy in women. Metastatic breast cancer remains an incurable disease and the spinal column is most likely affected by metastases. A significantly prolonged patient survival is the consequence of modern oncologic treatment options in the last decade. Surgical treatment of vertebral metastases has become an increasing focus for spine surgeons. With the turn of the millennium it was possible to classify breast cancer into four intrinsic phenotypes with various survival rates. Well known scoring systems help surgeons to evaluate the patient's prognosis and to choose adequate treatment options. However, tumor entities are differentiated without regard to the molecular subtypes. In this article we describe surgical treatment options in metastatic lesions to the spine with regard to molecular phenotypes of breast cancer malignancy. It is crucial to correctly estimate the expected survival time to plan invasiveness of therapy regarding metastatic spine surgery.
\end{abstract}

Keywords: Spine, metastases, breast cancer, phenotypes, subtypes, molecular level, prognosis

\section{INTRODUCTION}

Breast cancer is one of the most common cancer diseases metastasizing to the spine and the second leading cause of deaths in woman related to cancer $^{[1]}$. Modern treatment and diagnostic concepts including bisphosphonates go along with considerable longer survival times and a reduced rate of skeletal

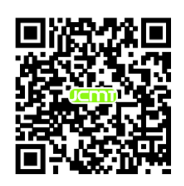


complications ${ }^{[2-4]}$. Until 2015 mean survival times of 27 months were described, actual studies report mean survival times of 55 months with a $85 \%$ incidence of spinal metastases ${ }^{[2-15]}$. An increased need for surgical treatment of complications related to spinal metastases is the consequence. Due to mortality and morbidity rates related to metastatic breast cancer every surgical treatment should be considered carefully. Well evaluated scoring systems (revised Tokuhashi-or Tomita score, revised Bauer score, Van-der-Lindenscore, Karnofsky index) help surgeons to individually chose optimal treatment methods and to predict life expectancies in cancer patients. But these scores only differentiate between tumor entities whereas respective tumor phenotypes are not taken into account ${ }^{[16-21]}$. With the turn of the millennium five different intrinsic subtypes of breast cancer were reported by means of gene expression profiles ${ }^{[14-22]}$. Four phenotypes are decisive in daily clinical routine: luminal A, luminal B, HER2-enriched and basal like/triple-negative. With an accordance of $70 \%-80 \%{ }^{[23]}$ these phenotypes are assessed with immunohistochemical pathologic markers (e.g., ER, PgR, HER2, KI-67/grading) as standardized gene expression profiling is available with partial coverage $^{[24]}$. In this article we describe the molecular parameters of metastatic breast cancer to predict survival time more precisely and to adequately calculate surgical therapies.

\section{ASSESSMENT OF PROGNOSIS}

The development of oncologic treatment options in primary breast cancer (in particular medical therapy) led to considerable improved survival rates in the last decade ${ }^{[2-9,12-15,25-27]}$. Immunohistochemical diagnostic tools provide a sufficient molecular phenotyping in breast cancer [Table 1].

Visceral, skeletal or cervical spine metastases, surgical complications and advanced patient's age are reported with different data in literature and therefore are not recommended as negative predictors ${ }^{[13]}$. In contrast, unimodal postoperative therapies, a disease-free interval less than 24 months, a high number of axillary lymph node metastases and progress after first-line therapy mark assured predictors of shorter survival ${ }^{[4,10,13]}$. Furthermore, patients' wishes and preferences, symptoms, biological age, intrinsic breast cancer subtype, tumor burden (number of metastasized organs) and prior therapies have to be taken into account ${ }^{[4]}$.

\section{MOLECULAR PREDICTORS}

Around the turn of the millennium, Sørlie und Perou ${ }^{[14,22]}$ published fundamental studies to classify breast cancer at the molecular level with relevance to clinical course of disease. As tumor-biological classifications increasingly become more complex, modern oncologic diagnostic and therapy options interact with highly specialized regulatory mechanisms of cells and cell cycles ${ }^{[8,28]}$. The actual breast cancer classification [Table 1] is based on histopathological examinations of a biopsy from the breast. Classifying breast cancer ${ }^{[1-3,5-9,12-15]}$ by estrogen receptor (ER), progesterone receptor (PgR), human epidermal growth factor 2 (HER-2) and a proliferation marker (KI-67) is global standard ${ }^{[23,24,28-33]}$. With these molecular genetic parameters breast cancer is differentiated into the four intrinsic phenotypes, which are clinically relevant [Table 1]. Hormone receptor status comprises the combination of ER and PgR status ${ }^{[3,8,12]}$. Furthermore, endocrine responsive subtypes (Luminal A and-B), triple negative and HER-2 over expressing immunophenotypes are differentiated ${ }^{[2,3,8,13,14,23]}$. Luminal-A and Luminal-B phenotypes are clinically distinguished by proliferation rate (e.g., KI-67), grading or a multigen signature ${ }^{[2,3,5-9,15,24,30]}$.

The common classification is based on the ubiquitous availability of these diagnostic methods, which enable comparable studies and therapy concepts. With regard to metastatic breast cancer mean survival times of 60 months are reported in the current literature ${ }^{[4,10,34]}$ in case of endocrine responsive phenotypes (Luminal-A and-B) compared to 26 months until the year $2015^{[2,3,35]}$. Compared to PGR positive (PgR+) status, patients with PgR negative (PgR-) status have a 59\% higher mortality risk ${ }^{[3]}$. In patients with hormone receptor negative (HR-) status the mean survival time is reduced by 11 months and mortality risk is $52 \%$ 
Table 1. Molecular phenotypes of metastatic breast cancer with related survival times ${ }^{[26]}$

\begin{tabular}{lllrr}
\hline Molecular Phenotype & \multicolumn{1}{c}{ Luminal A } & \multicolumn{1}{c}{ Luminal B } & HER2-enriched & Triple-negative-status \\
\hline & ER and PR positive & ER and/or PR positive & HER2-positive & ER and PR and HER2-negative \\
& Low Proliferation Rate (Ki-67) & High Proliferation Rate (Ki-67) & (Basal-like) \\
Mean survival time & 60 months & 60 months & 56.5 months & $15-19$ months \\
\hline
\end{tabular}

Table 2. Karnowsky Performance Scale from $1949^{[34]}$

\begin{tabular}{ll}
\hline Score & \multicolumn{1}{c}{ Parameter } \\
\hline 100 & Normal; no complaints; no evidence of disease \\
90 & Able to carry on normal activity; minor signs or symptoms of disease \\
80 & Normal activity with effort; some signs or symptoms of disease \\
70 & Cares for self; unable to carry on normal activity or to do active work \\
60 & Requires occasional assistance, but is able to care for most of their personal needs \\
50 & Requires considerable assistance and frequent medical care \\
40 & Disabled; requires special care and assistance \\
30 & Severely disabled; hospital admission is indicated although death not imminent \\
20 & Very sick; hospital admission necessary; active supportive treatment necessary \\
10 & Moribund; fatal processes progressing rapidly \\
0 & Dead \\
\hline
\end{tabular}

higher compared to hormone receptor positive $(\mathrm{HR}+)$ status $^{\left[{ }^{[6]}\right.}$. Biggest progress regarding survival times and therapy options was achieved in HER-2 enriched phenotypes in the last decade. Until some years a HER-2 positive status was associated as a negative predictor with a mean survival time of 5-9 months. After the introduction of new Anti-Her-2 therapeutics (Trastuzumab, Pertuzumab, T-DMI) the mean survival time is reported with 56.5 months ${ }^{[2-4,10,34,36]}$.

Whereas triple negative phenotypes (ER-, PgR-, HER-2-) were reported with a mean survival time of 6-9 months until the year 2015, actual data show a prolonged survival

time of 15-19 months ${ }^{[2-6,9,10,13-15,26-28,34,35,37,38]}$.

\section{SCORE SYSTEMS}

Life expectancy in metastasized tumor diseases is estimated with well known and evaluated score systems. The Karnofsky-Index [Table 2] dating from 1948 describes patients' general condition and physical resilience ${ }^{[17,21,39]}$. Furthermore, the Karnofsky-Index is part of different score systems (Tokuhashi and revised Tokuhashi score, Oswestry Disability Index, Van-der-Linden-Score $)^{[18,20,21,39,40]}$. Patients describe pain with the numeric or visual analogue scale (NAS/VAS) ${ }^{[41]}$. Vertebral stability is estimated by the Spinal Instability Neoplastic Score (SINS) [Tables 3 and 4] ${ }^{[21,42]}$, Harrington Score ${ }^{[21,43]}$ or Taneichi score ${ }^{[44]}$. The revised Tokuhashi score [Tables 5 and 6] ${ }^{[1,3,3]}$ and Tomita score [Tables 7 and 8$]^{[19]}$ are worldwide accepted to determine individual life expectancy in malignancy and to plan optimal treatment options. The modified Bauer score $^{[16]}$, Van-der-Linden score ${ }^{[20]}$ and Oswestry-risk index ${ }^{[39]}$ are named for the sake of completeness.

The revised Tokuhashi ${ }^{[18]}$ and Tomita score ${ }^{[19]}$ merely discern tumor entities (breast, prostate, lung, thyroid) and in both scores breast cancer is assessed with a favorable prognosis. The four different phenotypes of breast cancer are not included. A life expectancy limited to 5 to 9 months was published until 2015 concerning HER-2 enriched and triple negative phenotypes ${ }^{[2-6,6,10,13-15,26-28,34,35,37,38,45]}$. Therefore, modifications in the revised Tokuhashi ${ }^{[18]}$ and Tomita score ${ }^{[19]}$ were suggested ${ }^{[2,3]}$ and highly invasive anterior-posterior spine surgery should be evaluated critically. Based on present-day knowledge we can no longer emphasize these recommendations. Due to better oncologic treatment options actual studies estimate mean survival times of 15-19 months with regard to the triple negative and 56.5 months concerning HER-2 enriched phenotypes $^{[4,6,7,10,15,26]}$. A mean survival time of 15-19 months implies that several patients live longer and 
Table 3. Spinal Instability Neoplastic Score for the determination of vertebral body stability from $2010^{[23]}$

\begin{tabular}{llc}
\hline SINS parameter & \multicolumn{1}{c}{ Description } & Score \\
\hline Location & Junctional (CO-2, C7-T2, T11-L1, L5-S1) & 3 \\
& Mobile spine (C3-6, L2-4) & 2 \\
& Semirigid segments (T3-10) & 1 \\
Mechanical pain & Rigid segments (S2-5) & 0 \\
& Yes & 3 \\
Bone lesion & Sometimes & 1 \\
& No & 0 \\
Spinal alignment & Lytic & 2 \\
& Lytic/blastic (mixed) & 1 \\
Vertebral body collapse & Blastic & 0 \\
& Subluxation/translation present & 4 \\
De-novo-deformity (Kyphosis/Scoliosis) & 2 \\
Posterolateral involvement & Normal alignment & 0 \\
& $>50 \%$ collapse & 3 \\
& $<50 \%$ collapse & 2 \\
& No collapse with > 50\% body involved & 1 \\
& None of the above & 0 \\
\end{tabular}

Table 4. Interpretation of Spinal Instability Neoplastic Score ${ }^{[23]}$

\begin{tabular}{ll}
\hline Score & Stability \\
\hline $0-6$ & Stable \\
$7-12$ & Potentially unstable \\
$13-18$ & Unstable \\
\hline
\end{tabular}

Table 5. Revised Tokuhashi-Score parameter ${ }^{[48]}$

\begin{tabular}{|c|c|c|c|c|c|c|}
\hline Score & 0 & 1 & 2 & 3 & 4 & 5 \\
\hline Karnofsky-score (\%) & $10-40$ & $50-70$ & $80-100$ & & & \\
\hline Extraspinal bone metastases & 3 or more & $1-2$ & 0 & & & \\
\hline Spinal metastases & 3 or more & 2 & 1 & & & \\
\hline Frankel & Frankel A/B & Frankel C/D & Frankel E & & & \\
\hline Visceral metastases & Unremovable & Removable & None & & & \\
\hline Primary site of cancer & $\begin{array}{l}\text { Lung } \\
\text { Stomach } \\
\text { Bladder } \\
\text { Esophagus Pancreas } \\
\text { Osteosarcoma }\end{array}$ & $\begin{array}{l}\text { Liver, Gall Bladder } \\
\text { Unidentified }\end{array}$ & Others & $\begin{array}{l}\text { Kidney } \\
\text { Uterus }\end{array}$ & Rectum & $\begin{array}{l}\text { Breast } \\
\text { Thyroid } \\
\text { Prostata Carzinoid }\end{array}$ \\
\hline
\end{tabular}

Table 6. Iterpretation of the revised Tokuhashi-Score ${ }^{[48]}$

\begin{tabular}{lll}
\hline Score & \multicolumn{1}{c}{ Prognosis of survival } & \multicolumn{1}{c}{ Recommendation } \\
\hline $0-8$ & $85 \%$ of patients survive up to 6 months & Conservative therapy or palliative surgery \\
$9-11$ & $73 \%$ of patients survive $>6$ months; $30 \%>12$ Monate & Palliative surgery or in exceptions tumor excision \\
$12-15$ & $95 \%$ of patients survive $>12$ Monate & Tumor excision \\
\hline
\end{tabular}

these patients have to be filtered out. According to Tomita et al. ${ }^{[19]}$ and Tokuhashi et al. ${ }^{[18]}$ anterior spine surgery is indicated with a life expectancy of 12 months or more. If the patient is in good general condition and asks for surgery, we therefore recommend anterior-posterior techniques after critical evaluation. Furthermore, in 2012 Majeed $^{[45]}$ evaluated 55 patients according to the revised Tokuhashi ${ }^{[18]}$ and Tomita score $^{[19]}$ and reported continuously longer survival times than initially estimated. Majeed ${ }^{[45]}$ concluded, that prognosis of survival times is not reliable with the current scoring systems. 
Table 7. Tomita-Score ${ }^{[50]}$

\begin{tabular}{ll}
\hline Prognostic factor & Score \\
\hline Tumor growth & 1 \\
Slow (Breast, Prostata, Thyroid) & 2 \\
Moderate (Kidney, Uterus) & 3 \\
Rapid (Lung, Liver, Stomach, Colon, CUP) & \\
Viscerale metastases & 0 \\
None & 2 \\
Treatable & 4 \\
Not treatable & \\
Bone metastases & 1 \\
Solitary & 2 \\
Multiple & 2 \\
\hline
\end{tabular}

Table 8. Interpretation of the Tomita-Score ${ }^{[50]}$

\begin{tabular}{llll}
\hline Score & Mean survival time (months) & \multicolumn{1}{c}{ Treatment goal } & \multicolumn{1}{c}{ Recommendation } \\
\hline $2-3$ & 50 & Local long-term monitoring & Wide or marginal excision \\
$4-5$ & 23.5 & Local mid-term monitoring & Tumor bordering or intralesional excision \\
$6-7$ & 15 & Local short-term monitoring & Palliative surgery \\
$8-10$ & 6 & Terminal supply phase & Limited palliative surgery or no operative intervention \\
\hline
\end{tabular}

\section{THERAPEUTIC OPTIONS REGARDING SPINAL METASTASES}

With an incidence of $85 \%$ breast cancer metastases to the spine may lead to instability with pain, pathologic fractures and neurologic deficits in up to $10 \%^{[21,29,46]}$. Furthermore, there are severe socioeconomic aspects with $50 \%$ of woman have to change the working environment and $37 \%$ of woman involved can temporarily or permanently work no longer ${ }^{[4]}$. The primary therapy of painful metastases to the spine without relevant loss of stability is radiation and spine surgeons are not necessarily involved. Potentially unstable and painful lesions with a SIN Score $>7^{[42]}$ (+/-neurological deficits) are demonstrated to the consulting spine surgeons. Mandatory in every patient is a critical individual evaluation of prognosis to choose correct therapy options $^{[4,8,11,14,21,29,35,38,45-48]}$. Improving or maintaining the quality of life is the decisive therapeutic target in an incurable palliative situation. Wishes and priorities of these patients beside the status of metastases, previous therapy lines and general condition mainly influence the appropriate treatment ${ }^{[4]}$.

Beside local radiation orthotic devices are the main conservative treatment tools to stabilize the spinal column and reduce pain. Concomitantly as systemic osteoprotective therapy a bisphosphonate in combination with calcium and Vitamin D or Denosumab (monoclonal antibody) mark the standard additive medication in advanced breast cancer with bone metastases. With the best response in diverse tumor entities up to $62 \%$ of recalcification post radiatio is described in breast cancer spinal metastases ${ }^{[4,8,21,47,49,50]}$.

Various surgical treatment options can reduce pain and stabilize the spine. Bilateral, percutaneous balloon kyphoplasty as a minimal invasive treatment tool ${ }^{[13,36,46,47,49,51-54]}$ may not restore vertebral height but correlates with pain reduction. Thermal ablation of vertebral metastases with radio frequency ablation $(\mathrm{RFA})^{[50,53,55-57]}$ may be combined with kyphoplasty to reduce the likelihood of tumor recurrence. Posterior instrumentation with a screw and rod system is the gold standard in spine surgery to stabilize unstable tumor lesions. In case of spinal stenosis due to tumor the decompression of neural structures is reached via laminectomy and tumor debulking ${ }^{[13,29,43,46,47,50,52-55]}$. According to Tomita et al. ${ }^{[19]}$ palliative anterior surgery with vertebral body replacement (VBR) [Figures 1-3] can be recommended in patients with a life expectancy $>12$ months ${ }^{[46,47,58,59]}$. Highly invasive surgical options like en-bloc spondylectomy in Tomita technique or vertebral column resection with a mandatory 360 reconstruction [Figure 4] mark curative treatment options in case of solitary spinal metastases ${ }^{[46,47,58,59]}$. 

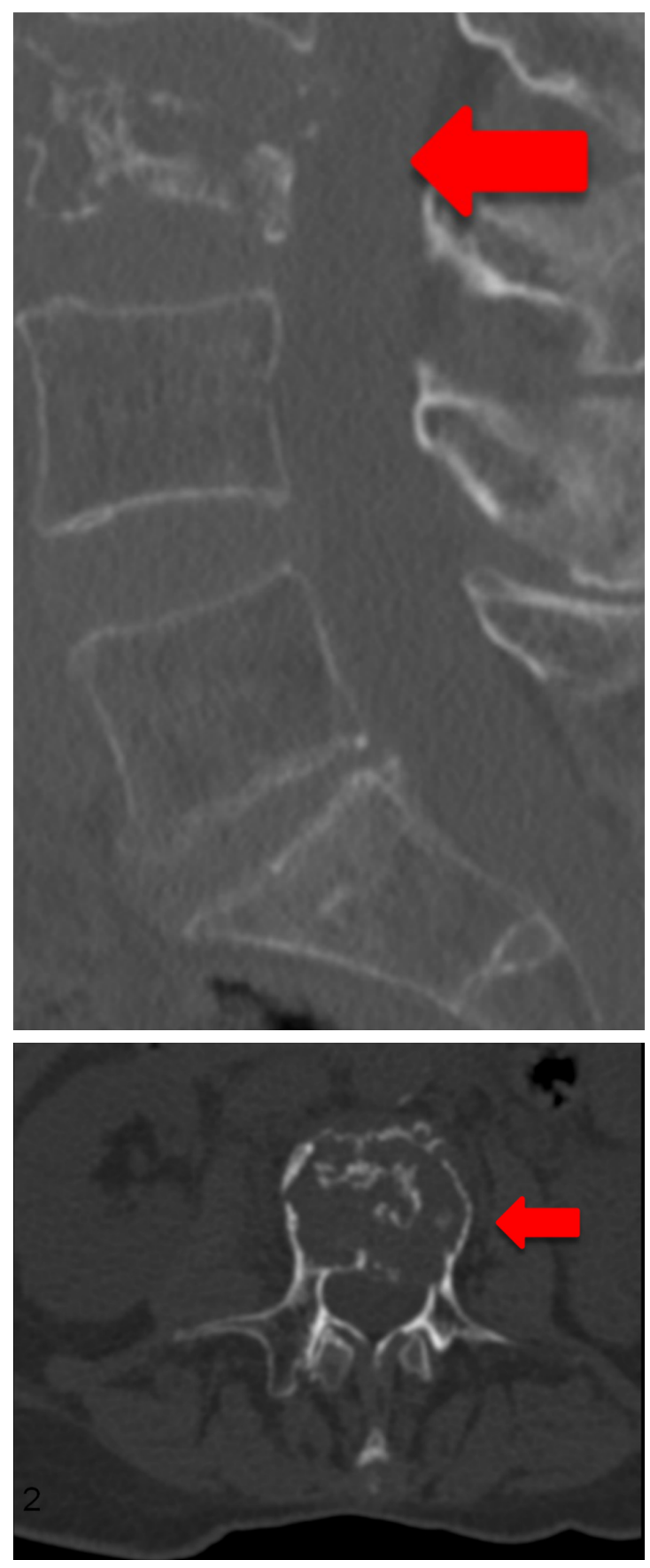

Figure 1. 73-year-old female patient with multiple metastatic breast cancer ER: 95\%; PgR: 0\%; HER2-Score 1+; Ki-67: 20\%. Sagittal and axial section of a total spine CT scan: unstable metastatic destruction of $\mathrm{L} 3$

The various techniques mentioned above can be combined as required. Additional measures like (partial-) resection of soft tissue, thoracic wall or pelvis with potential correction or reconstruction of deformity complete the port folio ${ }^{[47]}$. Modern adjuvant oncologic concepts comprise radio-, chemo- or hormone therapy $^{[8,47,50]}$.

Due to the wide range of therapy options mentioned above it is impossible for a sole attending physician to determine the individual therapeutical regimes. Such complex decision making demands an interdisciplinary setting like a tumor conference or board ${ }^{[4]}$. The spine surgeon determines the individual therapy of 


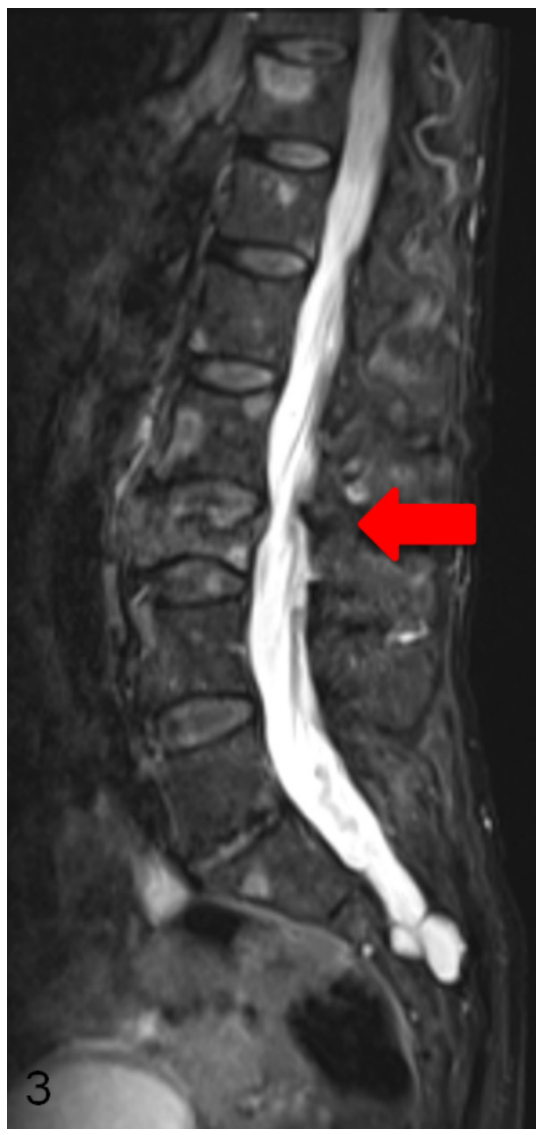

Figure 2. Sagittal section (T2-weighted) of a total spine MRI with contrast agent: metastatic destruction of L3 and multiple metastases

spinal metastases in breast cancer patients. An improved quality of life results of preserved mobility and autonomy with less pain. If possible, pathologic fractures and neurologic deficits up to paraplegia should be avoided $^{[2,3,8,18,19,29,42,43,47,50]}$.

\section{SPECIAL CASE: SOLITARY METASTASIS}

Prognostic statements are especially important in case of a solitary, locally curable metastasis (principle of limited metastasis ${ }^{[4]}$ ) and a treatable primary tumor in a curative way. For us the question was, if solitary metastasis with any phenotype is always to be treated the same way [Figure 5].

Either a Ct-controlled or an open biopsy finally ensures the histopathological phenotype. Until the year 2015 the curative therapeutic approach with en-bloc spondylectomy according to Tokuhashi et al ${ }^{[18]}$ and Tomita et al. ${ }^{[19]}$ was only recommended in hormone positive receptor status (luminal A and B) with a median survival time of 26 months $^{[2,13]}$. In triple-negative or Her-2 enriched phenotypes with an estimated survival time of 5-9 months, a limited posterior instrumentation (screw and rod system) and decompression of neural structures was indicated $^{[2,13]}$. Modern oncologic treatment concepts provide clearly longer survival times and therefore, according to Tokuhashi et al $\mathbf{X}^{8]}$, curative treatment options (mean survival time $>12$ months) can principally be applied to all phenotypes in breast cancer with solitary metastasis. In the worst case (triple-negative phenotype) the mean survival time is actually reported with $15-19$ months $\mathrm{s}^{[2-4,10,34,35]}$.

Indicating en-bloc spondylectomy will never be an automatism and controversial discussions in tumor boards can be expected. Critically evaluation of the individual wish, priorities, general condition, 


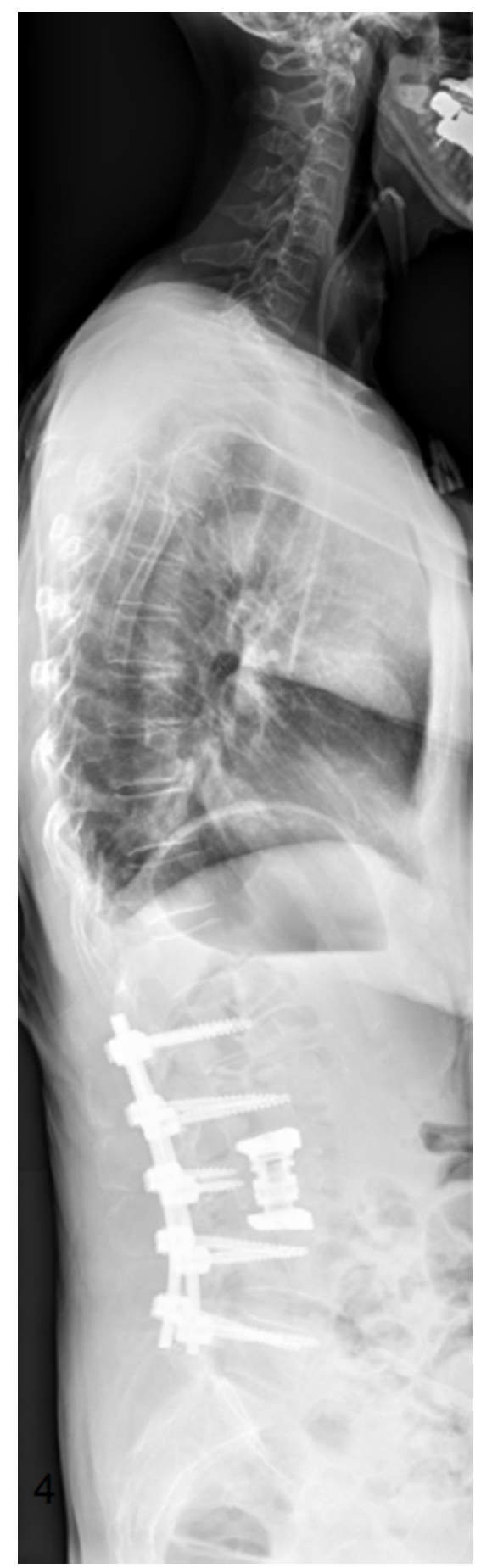

Figure 3. Postoperative sagittal total spine radiograph: posterior instrumentation L1-L5 with a screw and rod system, decompression via laminectomy, anterior stabilization with an insitu distractable vertebral body replacement of L3

comorbidities, previous lines of treatment and the biological age must influence the decision ${ }^{[4]}$. In tumor conferences a (neo-)adjuvant systemic therapy (endocrine therapy, Anti-HER-2 therapy, chemotherapy, osteoprotective therapy) is determined according to tumor load (TNM system) and biology. An adjuvant loco regional radiation therapy is mandatory in case of short edges of the resected areas in preparation slides $^{[4]}$. 


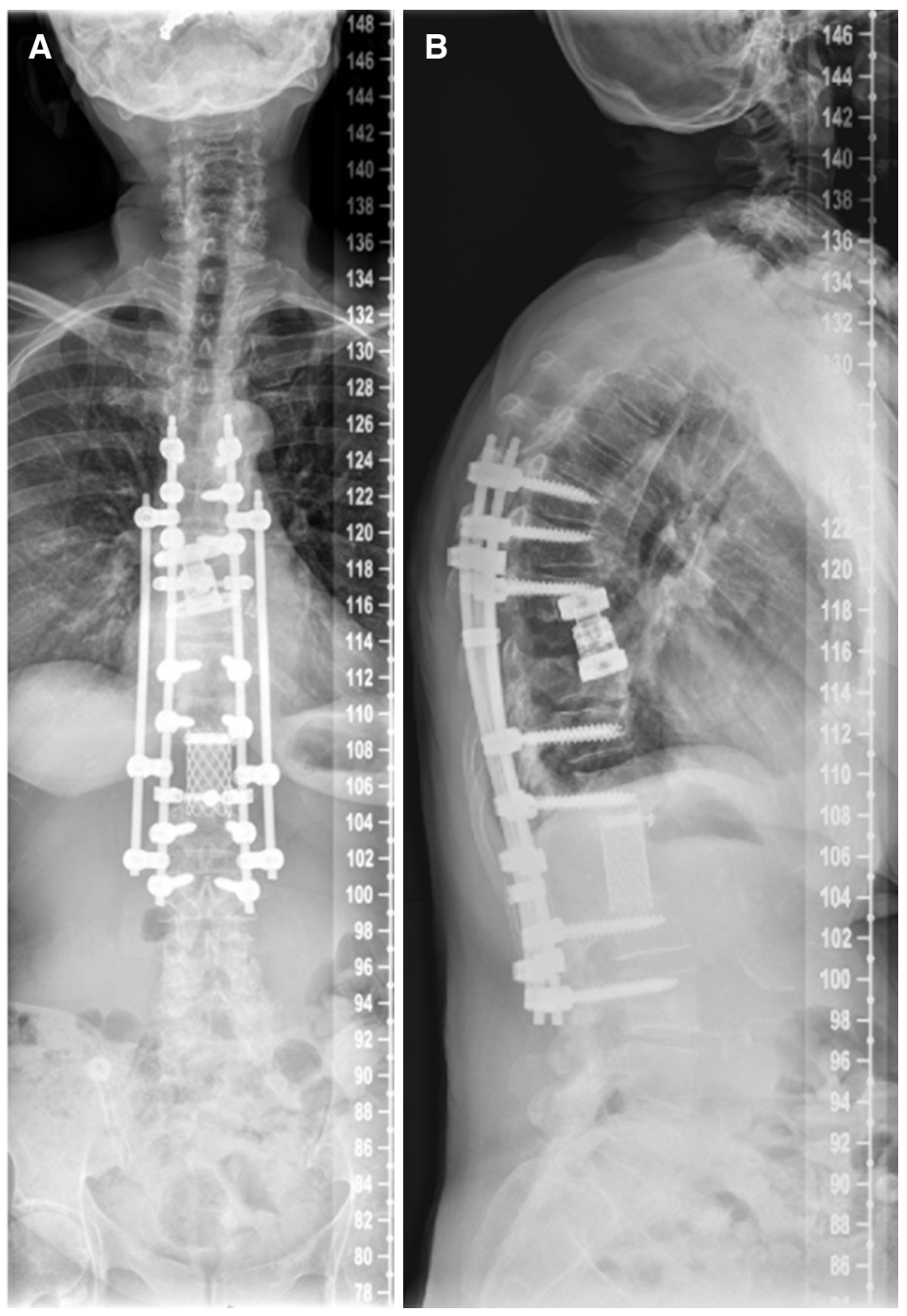

Figure 4. Two plane full spine radiographs of a 65 year old female patient with metastatic breast cancer(A, B). En-bloc spondylectomy in Tomita technique at the Th9 and L1 level with a time interval of 10 years. Anterior in situ distractible cage at the Th9 level and Harms cage at the L1 level, posterior 4-rod instrumentation Th6-L3

\section{CONCLUSION}

Evaluating prognosis by means of molecular tumor typing, previous course of disease and actual status of metastases is mandatory prior to elective surgery of breast cancer spine metastases.

Mean survival times of 60 months in endocrine responsive (Luminal A and B) phenotypes, 50 months in HER-2 enriched phenotypes and 15-19 months in triple negative phenotypes are described in actual literature.

The patients's general condition, biological age, intrinsic breast cancer subtype, comorbidities, tumor burden (number of metastases to organs) and previous therapies influence decision making.

Regardless of molecular phenotype solitary spinal metastases may be treated with a curative therapeutic approach.

Close cooperation of all experts participating interdisciplinary tumor boards are essential to determine adequate therapy strategies. 


\section{Therapy of solitary metastasis}

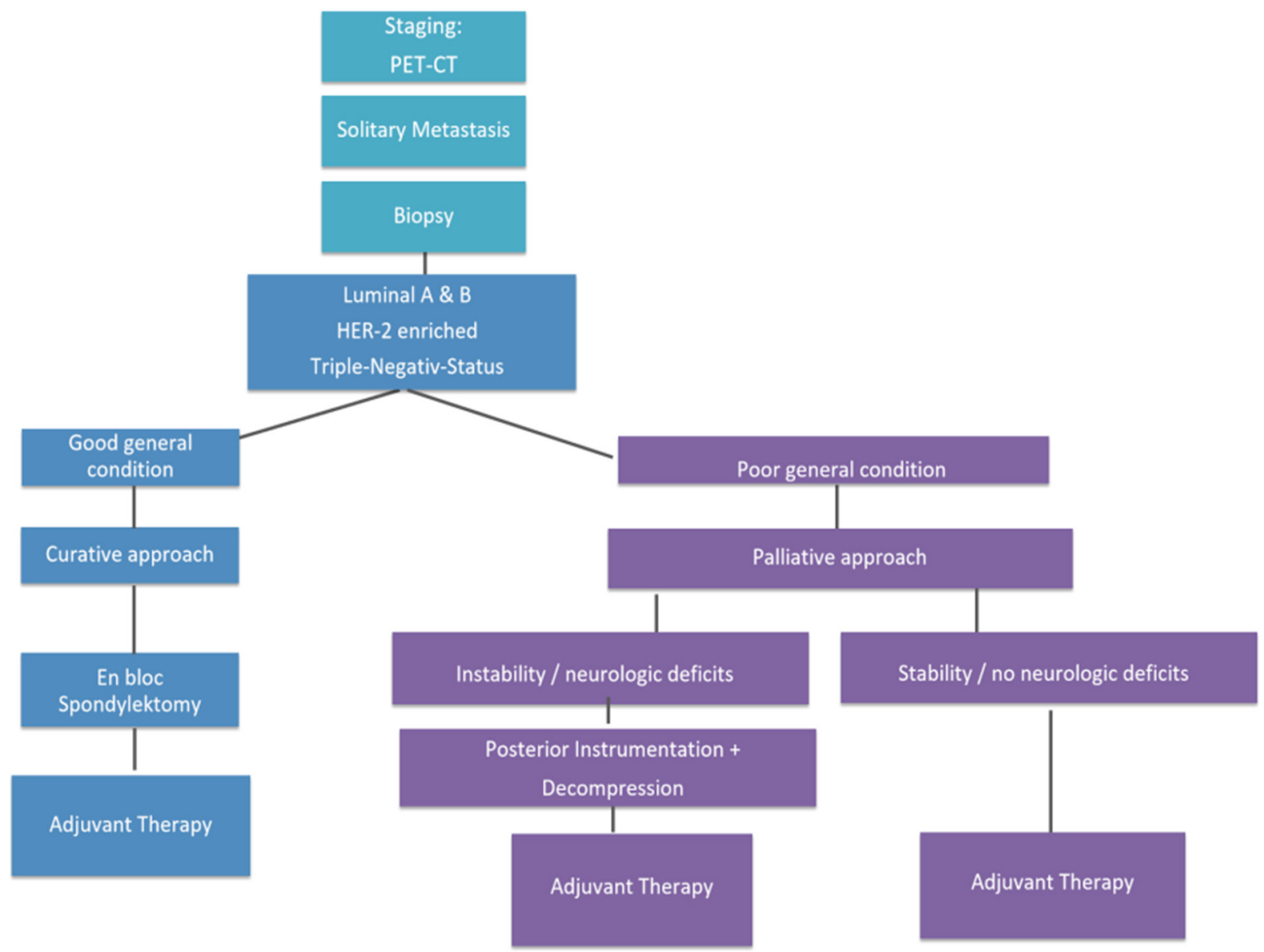

Figure 5. Heidelberg Spine Research Group Therapeutic Algorithm of Solitary Spine Metastasis in Breast Cancer

\section{DECLARATIONS}

\section{Authors' contributions}

Made substantial contributions to conception and design of the study and performed data analysis and interpretation: Adler D, Akbar M

Performed data acquisition, as well as provided administrative, technical, and material support: Pepke W

\section{Availability of data and materials}

Data is available for readers.

\section{Financial support and sponsorship}

None.

\section{Conflicts of interest}

All authors declared that there are no conflicts of interest.

\section{Ethical approval and consent to participate}

Not applicable. 


\section{Consent for publication}

Not applicable.

\section{Copyright}

(c) The Author(s) 2019.

\section{REFERENCES}

1. AWMF online. Available from: https://www.awmf.org/uploads/tx_szleitlinien/032-045OLl_S3_Mammakarzinom_2018-09.pdf. [Last accessed on 25 Apr 2019]

2. Bollen L, Wibmer C, Wang M, van der Linden YM, Leithner A, et al. Molecular phenotype is associated with survival in breast cancer patients with spinal bone metastases. Clin Exp Metastasis 2015;32:1-5.

3. Wang M, Jensen AB, Morgen SS, Wu CS, Sun M, et al. Survival analysis of breast cancer subtypes in patients with spinal metastases. Spine (Phila Pa 1976) 2014;39:1620-7.

4. Cardoso F, Costa A, Senkus E, Aapro M, André F, et al. 3rd ESO-ESMO international consensus guidelines for advanced breast cancer (ABC 3). Ann Oncol 2017;28:3111.

5. Elkablawy MA, Albasri AM, Mohammed RA. Ki67 expression in breast cancer. Correlation with prognostic markers and clinicopathological parameters in Saudi patients. Saudi Med J 2016;37:137-41.

6. Feeley LP, Mulligan AM, Pinnaduwage D. Distinguishing luminal breast cancer subtypes by Ki67, progesterone receptor or TP53 status provides prognostic information. Mod Pathol 2014;27:554-61.

7. Goldhirsch A, Wood WC, Coates AS, Gelber RD, Thürlimann B, et al. Strategies for subtypes dealing with the diversity of breast cancer: highlights of the St. Gallen international expert consensus on the primary therapy of early breast cancer 2011. Ann Oncol 2011;22:173647.

8. Harbeck N. Breast cancer: tumor biology-based concepts for surgical and drug treatment. Dtsch Med Wochenschr 2013;138:180-2. (in German)

9. Jiehua Li, Zhibai Chen, Ka Su, Jian Zeng. Clinicopathological classification and traditional prognostic indicators of breast cancer. Int J Clin Exp Pathol 2015;8:8500-5.

10. Kobayashi K, Ito Y, Matsuura M, Fukada I, Horii R, et al. Impact of immunohistological subtypes on the long-term prognosis of patients with metastatic breast cancer. Surg Today 2016;46:821-6.

11. Putzier M, Haschke F. Diagnostic standards for extradural tumors and metastases of the spinal column. Orthopäde 2013;42:691-9. (in German)

12. Sciubba DM, Gokaslan ZL, Suk I, Suki D, Maldaun MV, et al. Positive and negative prognostic variables for patients undergoing spine surgery for metastatic breast disease. Eur Spine J 2007;16:1659-67.

13. Sciubba DM, Goodwin CR, Yurter A, Ju D, Ziya LG, et al. A systematic review of clinical outcomes and prognostic factors for patients undergoing surgery for spinal metastases secondary to breast cancer. Global Spine J 2016;6:482-96.

14. Sorlie T, Perou CM, Tibshirani R, Geisler S, Johnson H, et al. Gene expression patterns of breast carcinomas distinguish tumor subclasses with clinical implications. Proc Natl Acad Sci U S A 2001;98:10869-74.

15. Tang P, Tse GM. Immunohistochemical surrogates for molecular classification of breast carcinoma: a 2015 update. Arch Pathol Lab Med 2016;140:806-14.

16. Bauer HC, Wedin R. Survival after surgery for spinal and extremity metastases. Prognostication in 241 patients. Acta Orthop Scand 1995;66:143-6.

17. Karnofsky DA, Burchenal JH. The clinical evaluation of chemotherapeutic agents in cancer. MacLeod CM (Ed), Evaluation of Chemotherapeutic Agents. Columbia Univ Press 1949;191-205.

18. Tokuhashi Y, Matsuzaki H, Oda H, Oshima M, Ryu J. A revised scoring system for preoperative evaluation of metastatic spine tumor prognosis. Spine (Phila Pa 1976) 2005;30:2186-91.

19. Tomita K, Kawahara N, Kobayashi T, Yoshida A, Murakami H, et al. Surgical strategy for spinal metastases. Spine (Phila Pa 1976) 2001;26:298-306.

20. Van der Linden YM, Dijkstra SPDS, Vonk EJ, Marijnen CA, Leer JW. Prediction of survival in patients with metastases in the spinal column: results based on a randomized trial of radiotherapy. Cancer 2005;103:320-8.

21. Von der Höh NH, Gulow J, Tschöke SK, Völker A, Heyde CE. Prognosis scores for spinal metastases. Orthopäde 2013;42:725-33.

22. Perou CM, Sørlie T, Eisen MB, van de Rijn M, Jeffrey SS, et al. Molecular portraits of human breast tumours. Nature 2000;406:747-52.

23. Bastien RR, Rodríguez-Lescure Á, Ebbert MT, Prat A, Munárriz B, et al. PAM50 breast cancer subtyping by RT-qPCR and concordance with standard clinical molecular markers. BMC Med Genomics 2012;5:44.

24. Blows FM, Driver KE, Schmidt MK, Broeks A, van Leeuwen FE, et al. Subtyping of breast cancer by immunohistochemistry to investigate a relationship between subtype and short and long term survival: a collaborative analysis of data for 10,159 cases from 12 studies. PLoS Med 2010;7:e1000279.

25. Coleman R, Powles T, Paterson A. Adjuvant bisphosphonate treatment in early breast cancer: meta-analyses of individual patient data from randomised trials. Lancet 2015;386:1353-61.

26. Godwin J, Gray R, Clarke M, Cutter D, Darby S, et al. Relevance of breast cancer hormone receptors and other factors to the efficacy of adjuvant tamoxifen: patient-level meta-analysis of randomised trials. Lancet 2011;378:771-84.

27. Wolff AC, Hammond ME, Hicks DG, Dowsett M, McShane LM, et al. Recommendations for human epidermal growth factor receptor 2 
testing in breast cancer: American society of clinical oncology/college of American pathologists clinical practice guideline update. J Clin Oncol 2013;31:3997-4013.

28. Harbeck N, Rody A. Lost in translation? Estrogen receptor status and endocrine responsiveness in breast cancer. J Clin Oncol 2012;30:686-9.

29. Crockard A, Bunger C, Harms J, Kawahara N, Mazel C, et al. Review of metastatic spine tumour classification and indications for surgery: the consensus statement of the global spine tumour study group. Eur Spine J 2010;19:215-22.

30. Early Breast Cancer Trialists' Collaborative Group (EBCTCG). Aromatase inhibitors versus tamoxifen in early breast cancer: patient-level meta-analysis of the randomised trials. Lancet 2015;386:1341-52.

31. Holtkamp W, Nagel GA, Wander HE, Rauschecker HF, von Heyden D. Hyperprolactinemia is an indicator of progressive disease and poor prognosis in advanced breast cancer. Int J cancer 1984;34:323-8.

32. Mullins M, Cheang MC, Leung S, Voduc D, Vickery T, et al. Supervised risk predictor of breast cancer based on intrinsic subtypes. J Clin Oncol 2009;27:1160-7.

33. Sinn P, Aulmann S, Wirtz R, Schott S, Marmé F, et al. Multigene assays for classification, prognosis, and prediction in breast cancer: a critical review on the background and clinical utility. Geburtshilfe Frauenheilkd 2013;73:932-40.

34. Chia SK, Speers CH, D'yachkova Y, Kang A, Malfair-Taylor S, et al. The impact of new chemotherapeutic and hormone agents on survival in a population-based cohort of women with metastatic breast cancer. Cancer 2007;110:973-9.

35. Wang M, Bünger CE, Li H, Wu C, Høy K, et al. Predictive value of Tokuhashi scoring systems in spinal metastases, focusing on various primary tumor groups: evaluation of 448 patients in the Aarhus spinal metastases database. Spine (Phila Pa 1976) 2012;37:573-82.

36. Swain SM, Baselga J, Kim SB, Ro J, Semiglazov V, et al. Pertuzumab, Trastuzumab, and Docetaxel in HER2-positive metastatic breast cancer. N Engl J Med 2015;372:724-34.

37. Peto R, Davies C, Godwin J, Gray R, Pan HC, et al. Comparisons between different polychemotherapy regimens for early breast cancer: meta-analyses of long-term outcome among 100,000 women in 123 randomised trials. Lancet 2012;379:432-44.

38. Ulmer B, Richter M, Cakir B. The Tokuhashi score: significant predictive value for the life expectancy of patients with breast cancer with spinal metastases. Spine (Phila Pa 1976) 2005;30:2222-6.

39. Balain B, Jaiswal A, Trivedi JM, Eisenstein SM, Kuiper JH, et al. The Oswestry risk index: an aid in the treatment of metastatic disease of the spine. Bone Joint J 2013;95-B:210-6.

40. Tokuhashi Y, Matsuzaki H, Toriyama S, Kawano H, Ohsaka S. Scoring system for the preoperative evaluation of metastatic spine tumor prognosis. Spine (Phila Pa 1976) 1990;15:1110-3.

41. Carlsson AM. Assessment of chronic pain. I. Aspects of the reliability and validity of the visual analogue scale. Pain 1983;16:87-101.

42. Fisher CG, Ryken TC, Bilsky MH, Shaffrey CI, Berven SH, et al. A novel classification system for spinal instability in neoplastic disease: an evidence-based approach and expert consensus from the spine oncology study group. Spine (Phila Pa 1976) 2010;35:E1221-9.

43. Harrington KD. Orthopedic surgical management of skeletal complications of malignancy. Cancer 1997;80:1614-27.

44. Taneichi H, Kaneda K, Takeda N, Abumi K, Satoh S. Risk factors and probability of vertebral body collapse in metastases of the thoracic and lumbar spine. Spine (Phila Pa 1976) 1997;22:239-45.

45. Majeed H, Kumar S, Bommireddy R, Klezl Z, Calthorpe D. Accuracy of prognostic scores in decision making and predicting outcomes in metastatic spine disease. Ann R Coll Sure Engl 2012;94:28-33.

46. Bullmann V, Liljenqvist UR. Operative treatment of spinal metastases. Orthopädie und Unfallchirurgie up2date 2010;5:279-94.

47. Heyde CE, Gulow J, von der Höh N, Völker A, Jeszenszky D, et al. Results-adapted operative treatment options for spinal metastases. Orthopäde 2013;42:734-45.

48. Von Salis-Soglio G, Prietzel T. Diagnostic methods in suspected malignant bone and soft tissue tumors. Orthopade 2002;31:595-607.

49. Cho JH, Ha JK, Hwang CJ. Patterns of treatment for metastatic pathological fractures of the spine: the efficacy of each treatment modality. Clin Orthop Surgn 2015;7:476-82.

50. Delank KS, Wendtner C, Eich HT, Eysel P. The treatment of spinal metastases. Dtsch Arztebl Int 2011;108:71-9.

51. Chen F, Xia YH, Cao WZ. Percutaneous kyphoplasty for the treatment of spinal metastases. Oncol Lett 2016;11:1799-806.

52. Josten $\mathrm{C}$, Glasmacher $\mathrm{S}$, Franck A. Indikationen und grenzen der minimal-invasiven stabilisierung der metastatisch befallenen wirbelsäule. Orthopäde 2013;42:755-64. Available from: https://link.springer.com/article/10.1007\%2Fs00132-013-2070-8. [Last accessed on 17 Apr 2019]

53. Toquart A, Graillon T, Mansouri N. Management of spinal metastasis by minimal invasive surgery technique: surgical principles, indications: a literature review. Neurochirurgie 2016;62:157-64.

54. Utzschneider S, Weber P, Fottner, Wegener B, Jansson V, et al. Prognosis-adapted surgical management of bone metastases. Orthopäde 2009;38:308, 310-2, 314-5.

55. Chiras J, Baragan H, Jean B, Rose M. Interventional radiology in bone metastases. Bull Cancer 2007;94:161-9.

56. Nakatsuka A, Yamakado K, Takaki H, Uraki J, Makita M, et al. Percutaneous radiofrequency ablation of painful spinal tumors adjacent to the spinal cord with real-time monitoring of spinal canal temperature: a prospective study. Cardiovasc Intervent Radiol 2009;32:70-5.

57. Zheng L, Chen Z, Sun M. A preliminary study of the safety and efficacy of radiofrequency ablation with percutaneous kyphoplasty for thoracolumbar vertebral metastatic tumor treatment. Med Sci Monit 2014;20:556-63.

58. Delgado-López PD, Rodríguez-Salazar A, Martín-Velasco V, Castilla-Díez JM, Martín-Alonso J, et al. Total en bloc spondylectomy for spinal tumours: technical aspects and surgical details. Neurocirugia 2017;28:51-66.

59. Gezercan Y, Çavuş G, Ökten AI. Single-stage posterolateral transpedicular approach with 360-degree stabilization and vertebrectomy in primary and metastatic tumors of the spine. World Neurosurg 2016;95:214-21. 